\title{
SEASONAL DYNAMICS OF NON-STRUCTURAL CARBOHYDRATES IN CLONAL PLANTS IN DIFFERENT HABITATS OF INLAND RIVER WETLANDS
}

\author{
ZhOU, Y. ${ }^{1,2}-$ JiAO, L. $.^{1,2^{*}}-$ LIU, X. R. ${ }^{1,2}-$ LI, F. ${ }^{1,2}$ \\ ${ }^{I}$ College of Geography and Environmental Science, Northwest Normal University, Lanzhou \\ 730070, China \\ ${ }^{2}$ Key Laboratory of Resource Environment and Sustainable Development of Oasis, Gansu \\ Province, China \\ ${ }^{*}$ Corresponding author \\ e-mail: jiaoliang@nwnu.edu.cn; phone: +86-139-1935-0195 \\ (Received 6 ${ }^{\text {th }}$ Aug 2021; accepted $1^{\text {st }}$ Oct 2021)
}

\begin{abstract}
Research on the temporal and spatial dynamics of non-structural carbohydrates (NSC) in plants and their distribution patterns in different modules will help understand the effects of environmental changes on plant growth and the ecological adaptation strategies of plants to heterogeneous environments. In this paper, Phragmites australis L., as a typical clonal plant in inland river wetlands, was analyzed to determine the characteristics of the variation in NSC and their compositions (soluble sugars: SS and starch: $S$ ) in early growth, mid-growth and later growth seasons at three habitats (wet, salt marsh, drought). The results showed that (1) the contents of NSC, SS and S in the whole plant and clonal modules of P. australis showed seasonal variations with gradually increasing trends in wet, salt marsh and drought habitats, but the SS contents of leaves displayed seasonal variations with decreasing trends; (2) there were differences in NSC's allocation strategies across clonal modules, showing that the NSC and SS were mainly invested in rhizomes and were transferred from leaves to stems, while $\mathrm{S}$ were mainly invested in stems and was transferred from rhizomes to roots during the transition from wet to drought habitat. The growth and survival strategies of clonal plants in inland river wetlands are dependent on the accumulation and allocation of NSC and their compositions. Meanwhile, these were the great significance guiding for the protection of inland river wetlands in the arid area.
\end{abstract}

Keywords: wetlands, Phragmites australis, resource allocation trade-offs, seasonal differences, environmental stress

\section{Introduction}

Non-structural carbohydrates (NSC) produced by plant photosynthesis are important energy supplies and temporary solute pools in plant growth and metabolism (Piper et al., 2017; Li et al., 2018). Variation in the NSC and the composition of their contents can reflect a balance between plant carbon absorption (photosynthesis assimilation) and carbon consumption (respiring and growth), indicating the trade-offs of carbohydrate distribution in plants (Shi et al., 2006). Many environmental factors in nature may limit plant growth and affect their normal physiological and metabolic functions of plants, which also change the carbohydrate contents in plants and the distribution of the proportions in different modules ( $\mathrm{Li}$ et al., 2008). At present, most studies on the relationship between NSC contents and environmental factors focus on alpine woody plants (Michelot et al., 2012; Guo et al., 2016), drought mosses (Fernandez et al., 2018), and aquatic plants (Eklöf et al., 2009; Pramanik et al., 2016). However, research on NSC contents in clonal plants in inland river wetlands is relatively scarce. Therefore, analyzing the changes of NSC in clonal plants in inland river wetlands can help us to understand the 
status the carbohydrate supply and provide important clues to reveal the adaptation mechanisms in particular habitats.

The different results related to the metabolic intensity and distribution proportions of NSC are caused by temporal and spatial interactions. Because of the different demands at different growth seasons, the contents of NSC and their composition in plants have seasonal periodic variation characteristics (Petrussa et al., 2018). However, the variation of NSC and their composition in different plants during different growing seasons showed diversity and complexity. For example, the starch contents in seedlings of Picea rubens in Vermont in the northeastern United States showed a decreasing trend by seasons (Schaberg et al., 2000). The NSC in the rhizomes of $P$. australis and Typha latifolia in Kahramanmaras, Turkey, showed a first increasing and then decreasing trend with season (Tursun et al., 2011). In addition, the NSC in Arisarum italicum and Atrophoderma maculatum in northeast Italy, P. australis and Spartina alterniflora in the Chongming Dongtan wetland in eastern China and Syntrichia caninervis in the Gurbantunggut Desert in northwest China showed gradually increasing trends with seasonal variations (Lv et al., 2013). There was no obvious seasonal variation in the leaf NSC contents of the main tree species in southwestern Basel of Switzerland (Hoch et al., 2003). Therefore, it is necessary to study the seasonal variations of NSC and their composition in different plants and diverse ecological systems.

Spatial heterogeneity resulting from different altitudes, drought and nutritional stress is also an important factor that restricts the distribution pattern of NSC resources in plants, which greatly affects plant growth and causes changes in the physiological and ecological adaptability of plants. The NSC contents of Pinus cembra in the Norbul Mountains of Switzerland and Picea meyeri in the Luliang Mountains of eastern China gradually increase with increasing altitude (Gričar et al., 2018). Under water stress, the starch contents of Pinus sylvestris in Scotland and Picea abies in Norway increased, and the soluble sugar contents of Laurus nobilis in southern Italy gradually decreased (Wang et al., 2015; Trifilò et al., 2017). Nutrient stress promoted the storage of carbohydrates of Larix olgensis in Northeast China, while it significantly reduced the total NSC contents of Stipa granddis and Leymus chinensis in western China (Ivanov et al., 2019). Therefore, the contents of NSC and their component in plants show different patterns in diverse habitats, which may be due to different adaptation mechanisms and strategies to adapt to different environments.

Clonal plants have strong environmental adaptability and wide distribution in natural ecosystems with the characteristics of infinite life, spatial mobility, reproductive diversity, resource sharing. In particular, clonal plants occupy an advantageous position and play a pivotal ecological role in grassland, tundra, wetlands, waters and other ecological systems (Ganie et al., 2015; Mudrák et al., 2017). At present, researches on clonal plants mostly focus on the integration and plasticity of clonal plants (Ooi et al., 2011; Wan et al., 2019), the trade-off between clonal growth and sexual reproduction (Xiao et al., 2015), the mechanism of resources sharing (Hutchings et al., 2008; Portela et al., 2018), and characteristics of life history and cloning diversity (Svensson et al., 2013). However, there is a paucity of researches on clonal plant NSC. The growth of Plant growth in natural systems is closely related to the accumulation and distribution of NSC (Lapointe, 2001; Douhovnikof et al., 2015). The doubling of $\mathrm{CO}_{2}$ concentration promoted the accumulation of starch and NSC in the aboveground and root parts of Bothriochloa ischaemum in western China (Xiao et al., 2017). The NSC contents of Ficus benjamina and Ficus binnendijkii in southern Asia were relatively stable and did not show a 
significant seasonal variation trend among modules (Veneklaas et al., 2005). The NSC contents of the roots of Elymus nutans on the Qinghai-Tibet Plateau significantly increased due to the delay in the chlorophyll degradation process with the warming autumn (Shi et al., 2015). Because of the complexity of the composition of non-structural carbohydrates in plants and the diversity of physiological activities involved, the dynamic changes of NSC contents will inevitably and significantly impact the structure and function of plant (Yin et al., 2009). However, the role of various NSC in clonal plants as signal substances in the ecosystem remains to be further explored.

Wetlands are ecosystems with many unique functions on earth, such as protecting biodiversity, regulating runoff, improving water quality and regulating the microclimate (Martyniuk et al., 2016; Finlayson et al., 2018). The ecosystems of inland river wetlands in special geographical locations could determine the high sensitivity of the area to environmental change and vulnerability to disturbance and destruction; these ecosystems are also difficult to re store to a balanced ecological status after destruction (Reis et al., 2017). P. australis is an advantageous plant in inland river wetlands with strong environmental adaptability and important ecological value; this species is a perennial root Poaceae clonal plant, which plays an irreplaceable role in maintaining the ecological balance, biodiversity and key zones of Earth's ecosystem (Liu et al., 2016; Atapaththu et al., 2017; Packer et al., 2017). To raise awareness of the trade-offs in P. australis resource allocation, extensive research has been carried out. Although some understanding of the resource allocation trade-offs for reeds has been developed, there has still been a lack of corresponding empirical studies. In this paper, $P$. australis individual in indifferent habitat gradients of inland river wetlands were taken as the research object, and the temporal and spatial variations in NSC were systematically explored. This paper aimed to solve two problems: (1) compare the temporal and spatial variations of NSC and composition contents in $P$. australis to clarify the adaptation strategies of plants to season and environment; (2) analyze of seasonal distribution of NSC and composition contents among the clonal modules of $P$. australis to explore the trade-offs of plant resource allocation. The research conclusions will have certain theoretical and applicable value for further understanding the ecological adaptation strategies of clonal plant populations and will provide a reference for ecological management in inland river wetlands of extremely arid areas.

\section{Materials and Methods}

\section{Study Site}

The Dunhuang Yangguan National Nature Reserve wetland is located in northwest China $\left(93^{\circ} 53^{\prime}-94^{\circ} 17^{\prime} \mathrm{E}, 39^{\circ} 39^{\prime}-40^{\circ} 05^{\prime} \mathrm{N}\right)$ with a total area of $8.82 \times 104 \mathrm{hm}^{2}$, an elevation of $1150-1500 \mathrm{~m}$, and is surrounded by desert and Gobi (Fig. 1). The study regions have a typical continental arid climate with a large temperature difference between day and night. The annual mean temperature is $9.3^{\circ} \mathrm{C}$. The annual total precipitation is $39 \mathrm{~mm}$ and the annual evaporation is $2465 \mathrm{~mm}$. There are nearly 200 springs in the reserve, which are rare salt marsh wetlands in arid desert areas. The soil in the wetland is mainly sandy soils, brown desert soils and meadow soils. The main vegetation types are temperate desert vegetation, mainly $P$. australis, Leymus secalinus, Lycium ruthenicum, Glycyrrhiza uralensis, Alhagi sparsifolia, Salicornia europaea and other plants. 


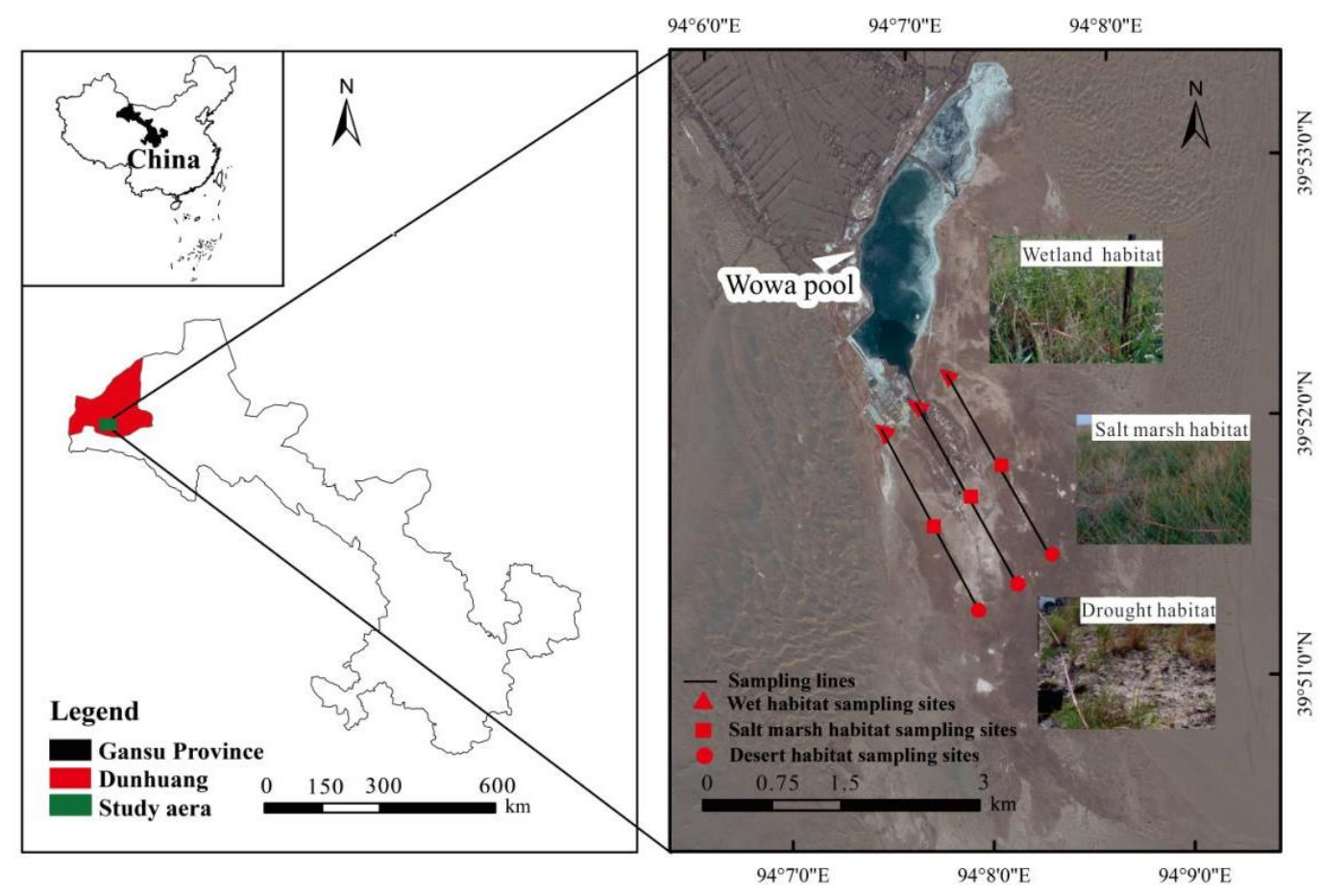

Figure 1. Study area and sampling point distribution

\section{Experimental Design and Measurements}

In May 2018 (early growth season), July (mid-growth season) and September (later growth season), three parallel sampling lines were set in the Dunhuang Yangguan National Nature Reserve along the direction from inside wetlands to outside droughts with distances of $500 \mathrm{~m}, 1500 \mathrm{~m}$ and $2500 \mathrm{~m}$ from the reservoir based on the coverage, density, frequency, height, and dry biomass of $P$. australis (Table 1). Three $5 \mathrm{~m} \times 5 \mathrm{~m}$ sample plots were set for each sampling line and the environmental factors such as altitude, latitude and longitude, geography and geomorphology of each sampling site were recorded (Table 2).

Table 1. Characteristics of P. australis population in different habitats

\begin{tabular}{c|c|c|c|c|c}
\hline Habitat & Coverage (\%) & Density (plants/m²) & Frequency (\%) & Height (cm) & Dry Biomass (g/m²) \\
\hline Wetland & $84.2 \pm 6.36 \mathrm{a}$ & $94.3 \pm 7.65 \mathrm{a}$ & $100.00 \mathrm{a}$ & $137.6 \pm 7.25 \mathrm{a}$ & $2047.95 \pm 15.23 \mathrm{a}$ \\
Salt marsh & $58.8 \pm 6.58 \mathrm{~b}$ & $37.9 \pm 10.40 \mathrm{~b}$ & $70.3 \pm 4.48 \mathrm{~b}$ & $74.5 \pm 4.84 \mathrm{~b}$ & $424.20 \pm 15.77 \mathrm{~b}$ \\
Drought & $24.2 \pm 1.67 \mathrm{c}$ & $8.40 \pm 3.93 \mathrm{c}$ & $40.7 \pm 6.72 \mathrm{c}$ & $22.49 \pm 2.84 \mathrm{c}$ & $35.55 \pm 7.78 \mathrm{c}$ \\
\hline
\end{tabular}

Different lowercase letters indicate significant differences between environmental gradients $(\mathrm{p}<0.05)$

Table 2. Characteristics of sampling sites in different habitats

\begin{tabular}{c|c|c|c|c}
\hline Habitat & Longitude $\left({ }^{\circ} \mathbf{N}\right)$ & Latitude $\left({ }^{\circ} \mathbf{E}\right)$ & Altitude (a.s.l., m) & Sample Area $(\mathbf{m})$ \\
\hline Wetland & $94^{\circ} 06^{\prime} 22^{\prime \prime}$ & $39^{\circ} 52^{\prime} 07^{\prime \prime}$ & 1125.67 & $5 \times 5$ \\
Salt marsh & $94^{\circ} 06^{\prime} 31^{\prime \prime}$ & $39^{\circ} 52^{\prime} 25^{\prime \prime}$ & 1121.12 & $5 \times 5$ \\
Drought & $94^{\circ} 06^{\prime} 46^{\prime \prime}$ & $39^{\circ} 52^{\prime} 56^{\prime \prime}$ & 1126.84 & $5 \times 5$ \\
\hline
\end{tabular}


Based on the characteristics of the clonal plant community, we randomly selected three whole $P$. australis plants with identical growth conditions from each sample plot. All above-ground and underground parts of the selected plants were harvested according to the clonal module collection method of full digging using "tracking and digging" based on the direction of the rhizomes in each plot (Harper, 1977; Dong et al., 2011). To deactivate the enzymes, the collected plant samples were baked at $105^{\circ} \mathrm{C}$ for 30 minutes. Then, the plant materials were divided into clonal modules such as leaves, stems, rhizomes and roots with scissors, and all the samples were numbered uniformly. All the samples were dried to a constant weight at $75-80^{\circ} \mathrm{C}$. The dried plant modules were crushed by a mixed ball mill (MM400, Retsch, Germany) and then sifted through a 100 mesh screen and immediately stored in a fridge $\left(0-4^{\circ} \mathrm{C}\right)$.

Soluble sugar contents were determined according to the anthrone method (Quentin et al., 2015). Samples of $P$. australis (leaves, stems, rhizomes, and roots) were weighed out to $0.2 \mathrm{~g}$ each (Landhäusse et al., 2018). And samples were extracted with deionized water. The supernatants collected by centrifugation at $6000 \mathrm{rpm}$ for $15 \mathrm{~min}$ were treated with $5 \%$ phenol and $98 \%$ sulfuric acid for $1 \mathrm{~h}$. Starch contents were also determined using the anthrone method. The sediment from the extract was dried, weighed and boiled with deionized water, and the supernatant was used for the determination of starch contents. The total NSC concentration was calculated from the soluble sugars and starch contents, whose absorbance values were determined by Lamda 35 (PE, Waltham, USA) at a wavelength of $620 \mathrm{~nm}$.

\section{Data Analysis}

The average soluble sugar and starch contents of each sample that were measured separately were tested for normal distribution and homovariance via Shapiro and Bartlett tests, and the non-normal and heteroscedastic samples were treated by variable transformation. The differences in NSC, soluble sugar and starch contents of the whole plant and its clonal modules in different growing seasons or habitats were tested by oneway ANOVA and Tukey-Kramer HSD, respectively, to compare their significant differences at $p<0.05$ and $p<0.01$. Linear mixed effect model was used to compare the effects of different plant modules, seasons and habitats on NSC and composition. ANOVA and Tukey-Kramer HSD were performed using SPSS 22.0 (SPSS Inc., Chicago, IL, USA). Linear mixed effect model was implemented by the "nlme" package in R 3.6.1 (R Core Team, 2015). All drawings were completed in Origin 8.0 (OriginLab Inc., Hampton, USA) software.

\section{Results}

\section{Effect Factors of NSC and Compositions in P. australis}

The effects of $P$. australis module, habitat, season and their interactions on NSC and compositions were different (Table 3). Among them, the effects of season, module and the interaction of habitat and module on NSC reached a highly significant level $(\mathrm{P}<0.001)$, the main effect of NSC variation was season, followed by modules and the interaction of habitat and module. Season, module, habitat and module-season interaction had significant effects on soluble sugars $(\mathrm{P}<0.05)$. Module and season were the most significant factors affecting soluble sugar variation. The effects of habitat, season and the interaction between habitat and module on starch reached a highly significant level 
$(\mathrm{P}<0.001)$, the most important factors affecting starch variation were season and modulehabitat interaction.

Table 3. Linear mixed effect model results for effects of NSC and Compositions in P. australis

\begin{tabular}{c|c|c|c|c|c|c|c|c|c}
\hline \multirow{2}{*}{ Influencing factors } & \multicolumn{3}{|c|}{ NSC } & \multicolumn{3}{c|}{ Soluble sugar } & \multicolumn{3}{c}{ Starch } \\
\cline { 2 - 10 } & $\begin{array}{c}\text { Standard } \\
\text { error }\end{array}$ & $F$ & $P$ & $\begin{array}{c}\text { Standard } \\
\text { error }\end{array}$ & $F$ & $P$ & $\begin{array}{c}\text { Standard } \\
\text { error }\end{array}$ & $F$ & $P$ \\
\hline Habitat & 1.18 & 2.033 & 0.15 & 0.89 & 14.31 & $<\mathbf{0 . 0 5}$ & 0.88 & 13.56 & $<\mathbf{0 . 0 5}$ \\
Season & 1.17 & 79.66 & $<\mathbf{0 . 0 0 1}$ & 0.88 & 29.03 & $<\mathbf{0 . 0 0 1}$ & 0.87 & 44.99 & $<\mathbf{0 . 0 0 1}$ \\
Module & 0.93 & 29.86 & $<\mathbf{0 . 0 0 1}$ & 0.70 & 23.33 & $<\mathbf{0 . 0 0 1}$ & 0.69 & 0.02 & 0.88 \\
Habitat $\times$ Season & 0.54 & 0.52 & 0.60 & 0.41 & 0.01 & 0.95 & 0.41 & 0.533 & 0.47 \\
Habitat $\times$ Module & 0.43 & 39.06 & $<\mathbf{0 . 0 0 1}$ & 0.32 & 3.116 & 0.08 & 0.38 & 58.14 & $<\mathbf{0 . 0 0 1}$ \\
Season $\times$ Module & 0.42 & 3.788 & $<\mathbf{0 . 0 5}$ & 0.34 & 11.34 & $<\mathbf{0 . 0 5}$ & 0.32 & 1.637 & 0.20 \\
Habitat $\times$ Season $\times$ Module & 0.20 & 0.69 & 0.68 & 0.15 & 0.148 & 0.70 & 0.15 & 0.01 & 0.94 \\
\hline
\end{tabular}

\section{Seasonal Variation of NSC Contents for P. australis in Different Habitats}

Under the conditions in the wet, salt marsh, and drought habitats, Fig. 2 shows that the NSC contents of the whole $P$. australis plant gradually increased with seasonal variations (wet: May 63.07\% < July 67.75\% < September 76.04\%, p < 0.05; salt marsh: May 60.92\% < July $67.69 \%$ < September 74.57\%, p < 0.05; drought: May $61.10 \%$ < July $67.64 \%$ < September $74.97 \%, \mathrm{p}<0.05)$. The increase in NSC contents for the whole P. australis plant in the later growth season was significantly greater than that in the first two growth seasons.
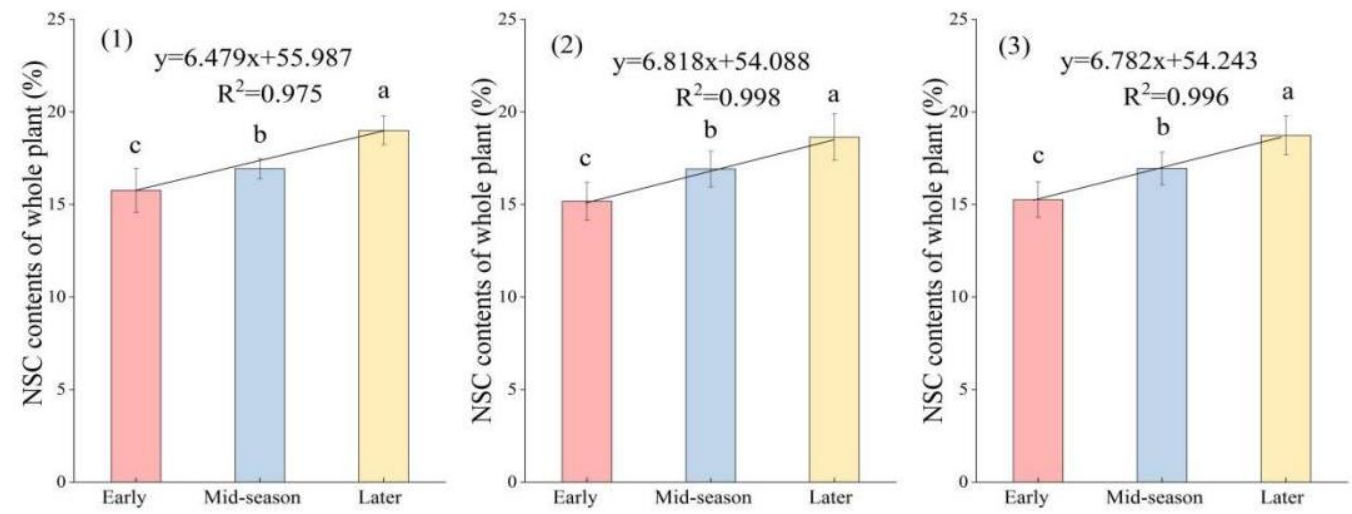

Figure 2. Seasonal dynamics of NSC contents for P. australis in wet (1), salt marsh (2), drought (3) habitats. (Different lowercase letters from same column indicate significant differences between seasonal variations $(p<0.05)$

In wet, salt marsh, drought habitats, the NSC contents of the clonal modules showed increasing trends from the early growth season to the later growth season (Fig. 3). Meanwhile, under the condition in wet habitats, there were no significant differences in 
the NSC contents of the leaf modules in the different growing seasons ( $p>0.05$ ), but there were significant differences in stem and root modules in the different growing seasons (p < 0.05). Fig. 3 also shows that there were significant differences in the NSC contents of the rhizome modules between the later growth season and the first two growth seasons $(\mathrm{p}<0.05)$. In salt marsh habitats, there were significant differences in the NSC contents of the leaf and rhizome modules in the later growth season and the first two growth seasons $(\mathrm{p}<0.05)$, of stem modules in the early growth season and the mid- and later growth seasons $(\mathrm{p}<0.05)$, and of root modules in each growth season $(\mathrm{p}<0.05)$. In drought habitats, the NSC contents of the leaf modules were not significantly different in any of the growth seasons ( $p>0.05)$, the stem and root modules were significantly different in each growth season $(\mathrm{p}<0.05)$, and rhizomes were significantly different in the later growth season and the early and mid-growth seasons $(\mathrm{p}<0.05)$. And the investment of NSC contents exhibited differences in the clonal modules among the three habitats, showing that the NSC were mainly invested in rhizomes and were transferred from leaves to stems from wet to drought habitats.

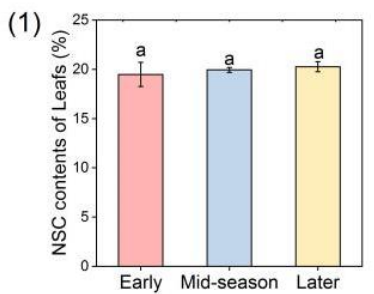

(2)

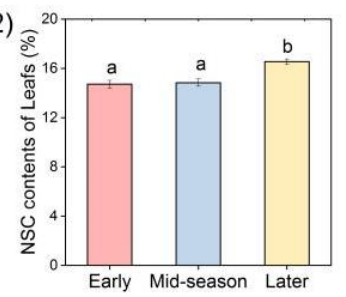

(3)

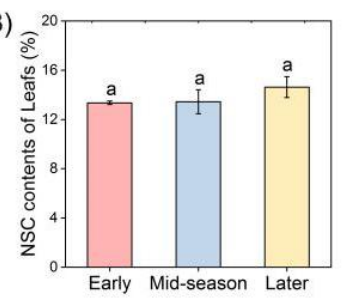

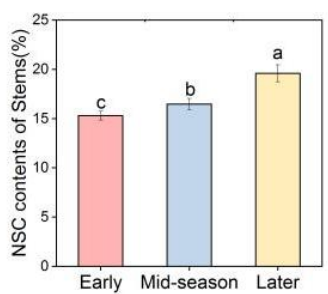
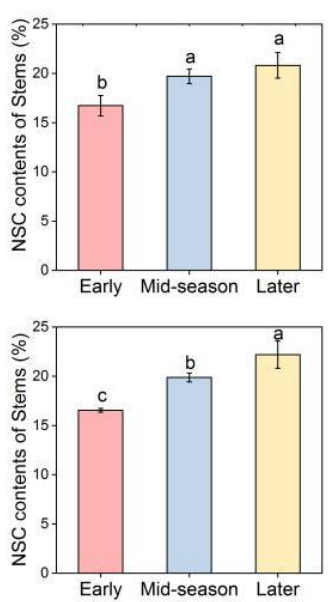
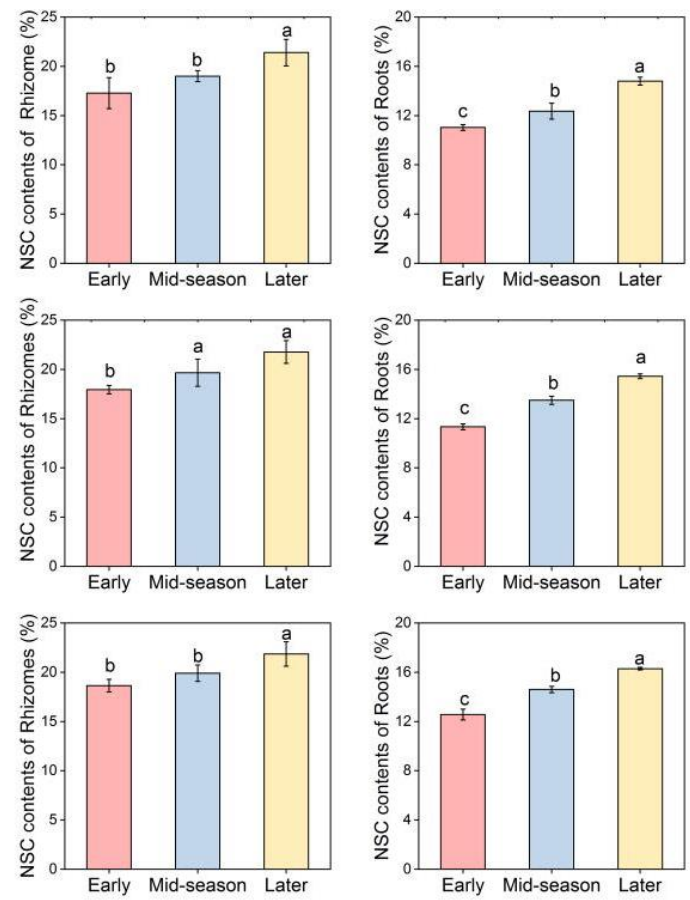

Figure 3. Seasonal dynamics of NSC contents of clonal modules for P. australis in wet (1), salt marsh (2), drought (3) habitats (Different lowercase letters from same column indicate significant differences between seasonal variations $(p<0.05)$

\section{Seasonal Dynamics of Soluble Sugar and Starch Contents for P. australis in Different Habitats}

In the wet, salt marsh, and drought habitats, the soluble sugar contents and starch contents of the whole $P$. australis plant showed increasing trends with growing seasonal variations (Figs. 4 and 5). In the wet habitat, the main manifestations in the soluble sugar and starch contents were in the early growth season (sugar: $21.94 \%$ and starch: $41.13 \%$ ) < mid-growth season (sugar: $24.21 \%$ and starch: $43.54 \%$ ) < later growth season (sugar: 
$27.01 \%$ and starch: $49.03 \%$ ). In the salt marsh habitat, the main manifestations in the soluble sugar and starch contents were in the early growth season (sugar: $22.53 \%$ and starch: $38.39 \%$ ) < mid-growth season (sugar: $26.17 \%$ and starch: $41.52 \%$ ) < later growth season (sugar: 29.29\% and starch: 45.68\%). In the drought habitat, the main manifestations were in the early growth season (sugar: $25.21 \%$ and starch: $35.89 \%$ ) < mid-growth season (sugar: $29.13 \%$ and starch: $38.51 \%$ ) < later growth season (sugar: $31.05 \%$ and starch: $43.92 \%$ ). Under the conditions in the wet, salt marsh, and drought habitats, the soluble sugar contents of the whole plant were significantly different in each growth season $(\mathrm{p}<0.05)$, but the starch contents of the whole plant were significantly different between the later growth season and the first two growth seasons $(p<0.05)$.
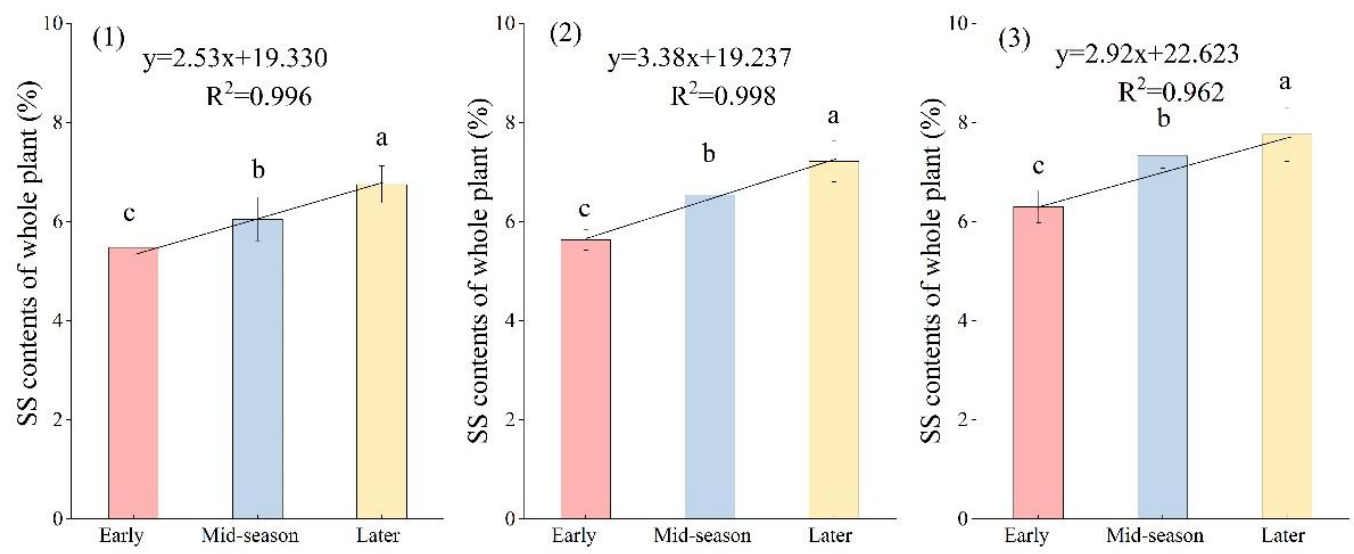

Figure 4. Seasonal dynamics of soluble sugar contents for P. australis in wet (1), salt marsh (2), drought (3) habitats. (Different lowercase letters from same column indicate significant differences between seasonal variations ( $p<0.05$ ), and ss represent soluble sugar)
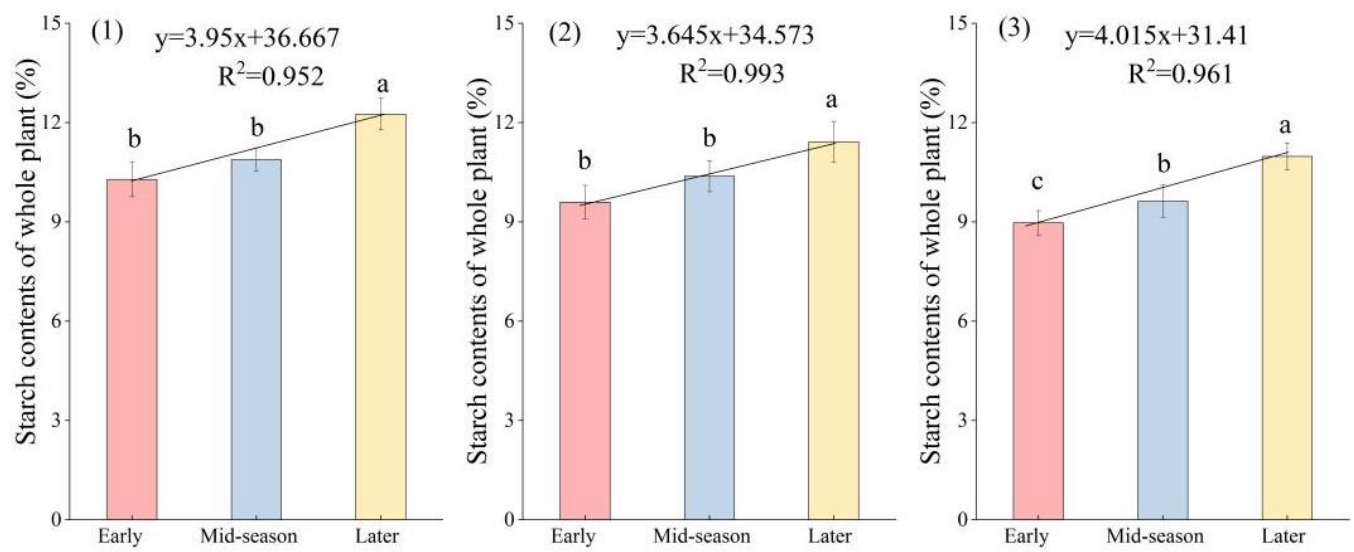

Figure 5. Seasonal dynamics of starch contents for $P$. australis in wet (1), salt marsh (2), drough (3) habitats. ((Different lowercase letters from same column indicate significant differences between seasonal variations $(p<0.05)$

In the wet habitats, the content of soluble sugar in leaf modules showed increasing trends and starch showed decreasing trends with seasonal variations. The content of soluble sugar in the stem, rhizome and root modules showed an increasing trend with 
seasonal variations. The soluble sugar contents invested in leaf and rhizome modules were significantly higher than those in stem and root modules. In the salt marsh habitats, the soluble sugar contents in leaf modules decreased trend. The contents of soluble sugar in stems, rhizomes and roots increased and exhibited variations. Meanwhile, the soluble sugar contents invested in leaf and rhizome modules were significantly higher than those in the stem and root modules. In the drought habitats, the contents of soluble sugar in leaf modules decreased and starch showed increasing trends with seasonal variations. The content of soluble sugar in the stem, rhizome and root modules increased with seasonal variations. Meanwhile, the soluble sugar contents invested in the stem and rhizome modules were significantly higher than those in the leaf and root module (Fig. 6).

(1)

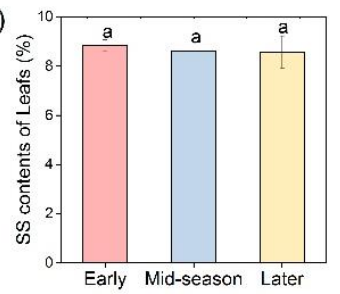

(2)

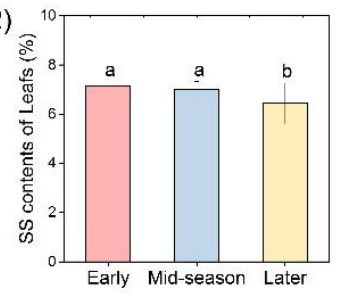

(3)

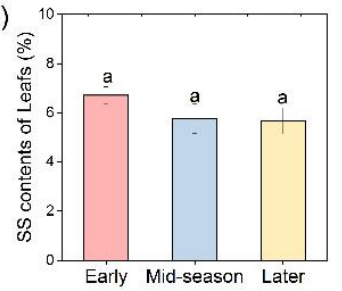

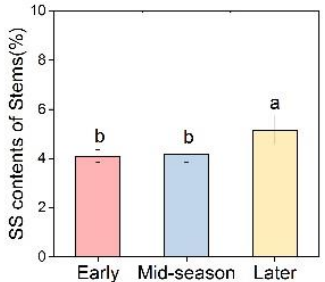
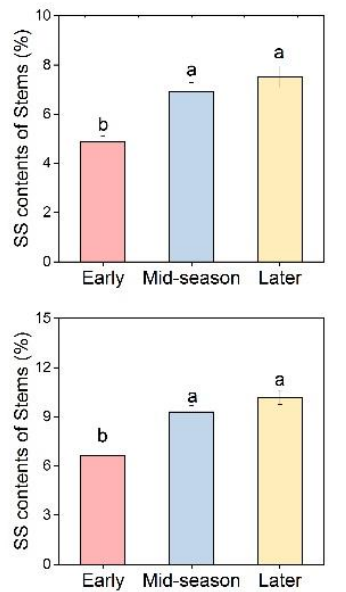
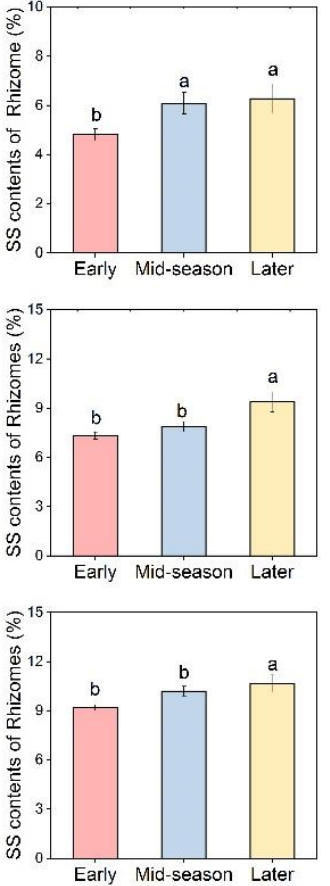
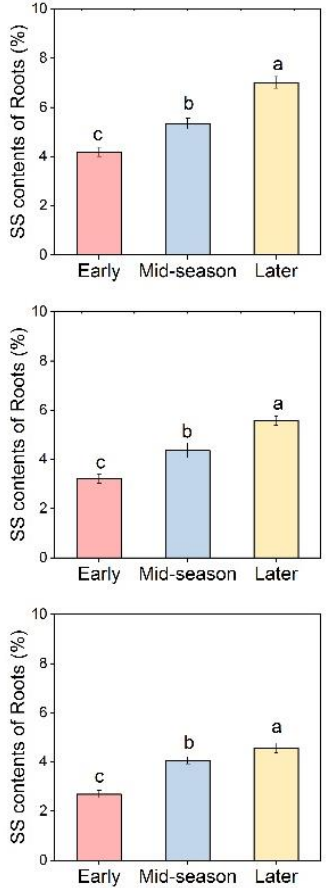

Figure 6. Seasonal dynamics of soluble sugar contents of clonal modules for P. australis in wet (1), salt marsh (2), drought (3) habitats. (SS is soluble sugar, different lowercase letters from same column indicate significant differences between seasonal variations $(p<0.05))$

In the wet habitats, the content of starch in the stem, rhizome and root modules showed an increasing trend with seasonal variations. The starch content invested in the stem and rhizome modules were significantly higher than those in leaf and root modules. In the salt marsh habitats, the starch showed an increasing trend with seasonal variations. The content of starch in stem, rhizome and root modules increased and exhibited variations. Meanwhile, the starch content invested in the stem and rhizome modules were significantly higher than those in the leaf and root modules. In the drought habitats, the content of starch in leaf modules decreased and showed increasing trends with seasonal variations. The content of starch in the stem, rhizome and root modules increased with seasonal variations. Meanwhile, the starch contents in the stem and root modules were significantly higher than those in the leaf and rhizome modules (Fig. 7). 
(1)

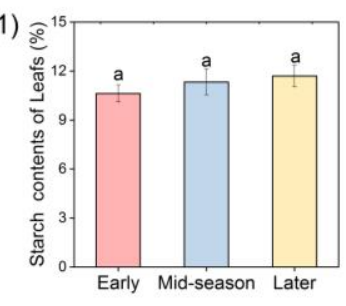

(2)
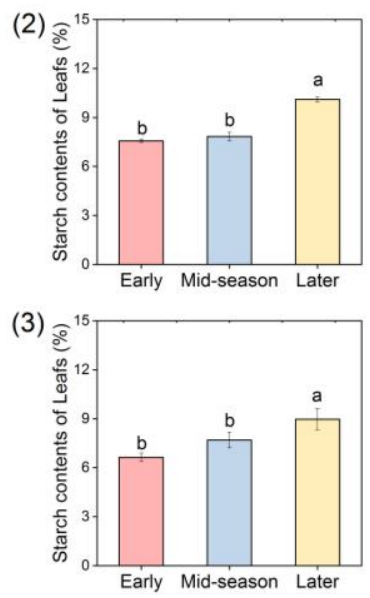
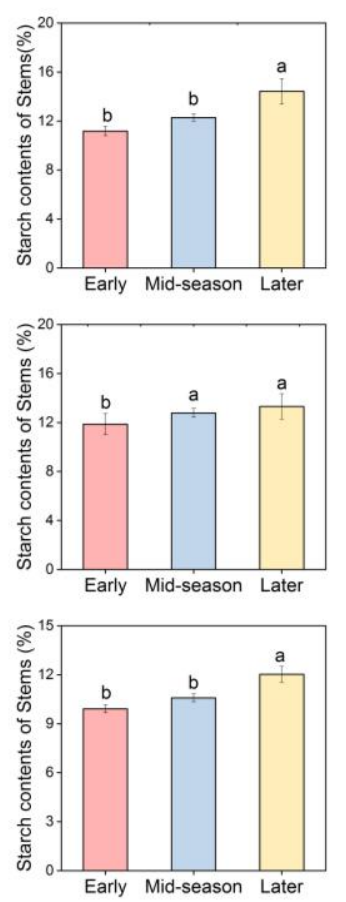
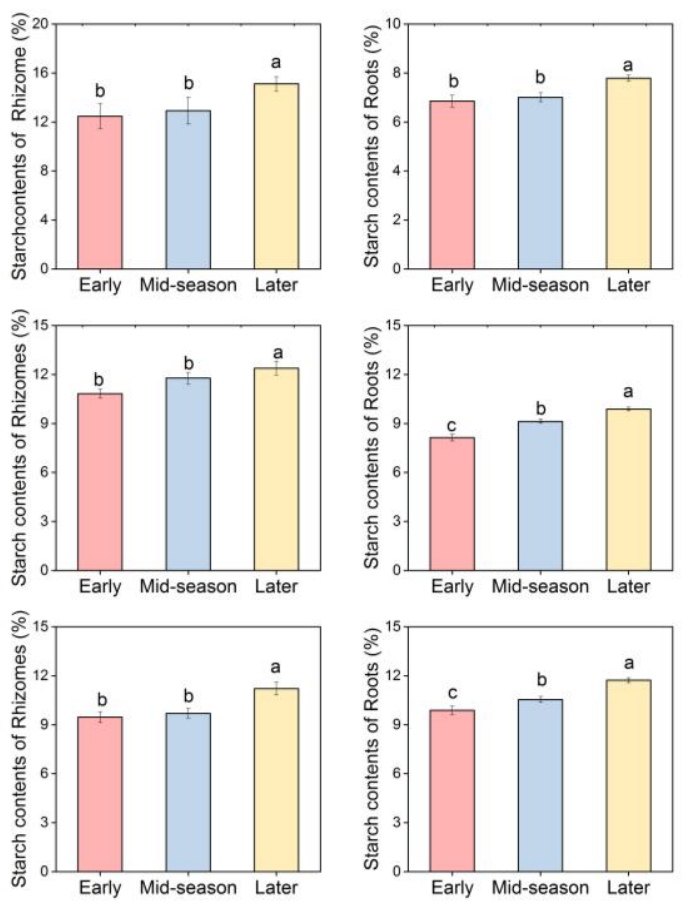

Figure 7. Seasonal dynamics of starch contents of clonal modules for P. australis in wet (1), salt marsh (2), drought (3) habitats. Different lowercase letters from same column indicate significant differences between seasonal variations $(p<0.05)$

\section{Discussion}

\section{Temporal and Spatial Variations of NSC and Compositions in P. australis}

Non-structural carbohydrates (NSC) are the main energy source for plant growth, reproduction and survival (Sørensen et al., 2018). The NSC contents and concentrations can reflect the carbon supply status of plants, and represent the growth and survival ability of plants as well as their adaptability to external stress disturbances (Würth et al., 2004; Lloret et al., 2018). Recent studies have found that plants are highly sensitive to changes in environmental conditions and respond quickly to very small changes in physiological cell and molecular levels (Myers and Kitajima, 2007). The results of our study revealed that the contents of NSC, soluble sugar and starch in the whole and clonal modules of $P$. australis showed consistent seasonal trends in wet, salt marsh and drought habitats (Figs. 2, 3, 4, 5, 6 and 7). Environment heterogeneity has a uniform effect on the contents of NSC, soluble sugars and starch in plants. It shows an ecological adaptation strategy of plants under environmental stress.

The seasonal distribution pattern of NSC and the efficiency of transport integration affect the growth and survival of plants in the community. In wet, salt marshes and drought habitats, the NSC contents of the whole $P$. australis plant showed significant changes with seasonal variations, showing increasing trends (Figs. 2, 4 and 5). Increasing the storage of NSC is one of the strategies for plants to cope with adverse environments or potential stress (Chaves et al., 2008). This strategy is used because NSC, as the main energy and carbon supplier for plant growth, can act as a buffer when plant photosynthesis is insufficient (Loewe et al., 2000; Sala et al., 2012). At the end of growth, the NSC contents in plants reach the maximum at one year, which lays the material foundation for 
the unfavorable weather conditions in winter and the formation of plant nodule germination and tillering in the subsequent year (Borrell et al., 1989; Orthen et al., 2004). NSC begins to be consumed in the early season of plant growth in the following year, and plants converted more photosynthesis products into fiber for the accumulation of plant biomass during the mid-growth season. The results of the study on the P. australis population in eastern China confirm this conclusion. At the same time, under the condition of habitat stress, the normal physiological metabolic activities of most plants are inhibited, manifesting as the restriction of carbohydrate synthesis into structural substances. In addition, environmental stress could also cause a barrier to the transmission of NSC, which would also reduce the availability of NSC used for metabolism and further affect the NSC contents (Yu et al., 2014). Therefore, the change of NSC contents in plants could represent a way of adapting to the heterogeneous environments.

Among NSC compositions, soluble sugar plays an important role in regulating osmotic pressure, while starch acts as organic storage and has effective functions in plant resistance to harsh environments, which can be transformed to each other when the environment changes (Nathan et al., 2010; Purdy et al., 2015). Our study results manifested that the contents of soluble sugar and starch in the whole plant of $P$. australis varied significantly with the seasons in the three habitats, showing the smallest contents (soluble sugar: $21.94 \%, 24.21 \%, 27.01 \%$, starch: $35.89 \%, 38.51 \%, 43.92 \%$ ) in the early growth season and the largest contents (soluble sugar: $25.21 \%, 29.13 \%, 31.05 \%$, starch: $41.13 \%, 43.54 \%, 49.03 \%$ ) in the later growth season (Figs. 2, 4 and 5). This result occurred because the photosynthesis of plants is sufficient during the early growth season and the contents of soluble sugar that are synthesized in plants are used for plant growth. At this time, a large amount of surplus starch was temporarily stored in plants as the seasons change and growth under these environmental conditions results in weakened photosynthesis and insufficient of photosynthetic supply, which was unbalanced with soluble sugar contents during the acquisition and expenditure. Additionally, starch could be transformed into soluble sugar to provide energy for plant growth and reproduction and maintain normal physiological function (Machado et al., 2017). This higher the distribution trade-off can make the plant growth and sustainable development due to the rational seasonal allocation of sugar and starch in plants. Therefore, plants are not only dependent on the total NSC content, but also need a balance dimension of sugar and starch to survive difficult environments and seasons. This finding indicates that the different distribution mechanisms of sugar and starch in plants are a positive adaptive response to environmental conditions, that is, the more difficult and harsh the habitat conditions are during plant growth, the more obvious and active the protection strategies of plants. In the course of long-term adaptive evolution, clonal plants have developed ecologically adaptive responses to effectively utilize heterogeneous resources and resist various environmental stresses.

\section{Temporal and Spatial Variations of NSC and Compositions among Clonal Modules of P. australis}

Variations in the location and contents of NSC in plants are associated with different seasons of growth and development. NSC metabolism, to a large extent, affects the growth and development of plants and their responses to the environment, showing seasonal distribution trade-offs of carbohydrate contents among different modules (Banerjee and Roychoudhury, 2016). Our study results showed that the NSC contents of clonal modules of $P$. australis exhibited different trends with seasonal dynamics, mainly 
manifesting as the increasing trend of NSC contents in leaf, stem, rhizome and root modules (Figs. 6 and 7). This result was consistent with the conclusion of previous studies that revealed that plant carbon acquisition and consumption were seasonally dependent (Mataa et al., 1996). This result occurred because most of the NSC in plants were used during the growth of leaf modules in the early growth season. Plants gradually accumulate NSC into stems to maintain survival and improve the utilization efficiency of nutrients in the body by enhancing cell osmotic pressure and cell metabolic activity and promoting plant growth (Regier et al., 2010). Meanwhile, plant biomass was basically reached a stable level at the later stage of growth, and other clonal modules began to store large amounts of NSC for plant growth and development in the next year. Hence, a large amount of NSC accumulates in stems and rhizomes, asexual reproduction dependent on rhizomes was selected, plants invest more NSC in rhizome in order to escape from patches with poor resource levels to patches with better conditions (Sevanto et al., 2013). The same results were obtained from the study of NSC in roots, stems and leaves of Zygophyllum xanthoxylon in the Alaska region of China (Sun et al., 2020). Studies have confirmed that variation of the NSC contents and transfer between clonal modules in plants is most likely the signal generated by plants on environmental changes, which can control the expression of genes in plants, effectively mitigate the damage caused by environmental stress on plants, and further regulate the growth and development of plants (Li et al., 2018). Therefore, research on the seasonal dynamics and distribution trade-offs of NSC among clonal modules is of major importance for understanding the stability and survival of plants under different habitats and environmental stressors.

Sugar provides the carbon skeleton and energy for plants, and starch stores energy substances for a long time, which are the most important carbohydrate in plant storage modules. Therefore, the synthesis and decomposition of sugar and starch affect the whole process of plant growth and development (Savage et al., 2015; Kaur et al., 2016). Our study results showed that the soluble sugar and starch contents in clonal modules (except leaves) increased with seasonal variations in wet, salt marsh and drought habitats (Figs. 6 and 7). However, the contents of soluble sugar in leaves showed a decreasing trend, and starch contents showed an increasing trend. In the middle and later stages of growth, the decrease of sugar content in leaves was due to the obstruction of the photosynthesis process with the stomatal closure gradually increased and the gas exchange ability decreased between leaves and the outside in to prevent excessive water loss (Ge et al., 2012). At the same time, photosynthesis of plant leaves decreased during the mid and later growth seasons, and the soluble sugar used for growth was greatly inhibited. That was the soluble sugar contents invested in the growth of plant leaf modules would decrease and the starch contents would increase (Hinman and Fridley, 2018; Kleyer et al., 2018). In addition, our results also found that soluble sugar was transferred from leaves to stems, while starch was transferred from rhizomes to roots during the transition from wet to drought habitat. Allocate limited starch to roots to increase their ability to withstand stressful environments and induce root growth deeper into the soil to obtain more nutrients to adapt the harsh external environmental condition. The same results were obtained for the study of nutrient stoichiometry of $P$. australis in the northwest arid zone (Zhou et al., 2021). Therefore, the growth-priority strategy was selected depending on stems and roots types, which was a response trade-off to the stress environmental conditions (Jiao et al., 2020). Meanwhile, soluble sugars were transferred to stem modules and starch to root modules, which could allocate more photosynthetic products for growth, respiration and nutrient absorption based on the theory of optimal allocation of 
resources (Klein et al., 2014). To carry out normal physiological activities under various habitat gradients to resist and adapt to environmental stress, clonal plants could regulate the osmotic potentials of cells in plants, maintain certain energy and maintain certain swelling pressure through the mutual transformation of soluble sugar and starch contents between plant modules during the growth process (Qin et al., 2013; Wang et al., 2015).

The distribution pattern of plant NSC and its components is the result of multiple ecophysiological processes, influenced by environmental factors, and closely related to the adaptation strategies of plants. In our study, season were the most important factors affecting NSC, soluble sugars, and starch (Table 3). The same results were obtained from the study of the seasonal dynamics of the non-structural carbohydrate content of Syntrichia Caninervis in different habitats (Zhu et al., 2017), indicating that the growing $P$. australis itself has a high capacity for nutrient utilization and a large variability in the elements required at different growth stages (Cullen et al., 2005). In addition, module also plays an important role in $P$. australis NSC variation. This may be due to the different degree of demand and limitation of NSC and its components in different modules (Martinez et al., 2016). The interaction of modules and habitats also played an important role in NSC and starch of $P$. australis. It due to the significant variation in soil nutrient status under different habitats, thus affecting the uptake of NSC and starch by $P$. australis.

\section{Conclusion}

NSC are the main energy substances for plant life activities and an important regulatory substance for plants in response to environmental changes, and play a leading role in plant growth, development and survival strategies. The results showed that the NSC contents of the whole plant and clonal modules of $P$. australis increased with seasonal variations in wet, salt marsh and drought habitats. Meanwhile, the soluble sugar and starch contents of the whole plant and stem, rhizome and root modules of $P$. australis increased with seasonal variations, but the soluble sugar contents decreased and the starch contents increased in leaves with seasonal variations. The investment of NSC and their compositions contents exhibited were differences in the clonal modules among the three habitats, showing that the NSC and soluble sugar were transferred from leaves to stems, while starch was transferred from rhizomes to roots during the transition from wet to drought habitats. These variation models reflect the physiological activities of plants and reveal the response and adaptation of plants to environmental changes, which can serve as a reference for the growth strategies and resource trade-offs of clonal plants in inland river wetlands. At the same time, research on the changing characteristics and response rules of non-structural carbohydrates in different seasons and habitats can further reveal the competition mechanism, enrich the competition theory and provide a theoretical basis for formulating and applying the restoration and reconstruction techniques of degraded vegetation and water resource shortages in extremely sensitive and fragile ecosystems.

Acknowledgements. This work was supported by the National Natural Science Foundation of China (Grant No. 41861006), the Natural Science Foundation of Gansu Province (No. 20JR10RA093), and the Research Ability Promotion Program for Young Teachers of Northwest Normal University (NWNU-LKQN2019-4). We also thank the anonymous referees for helpful comments on the manuscript. 


\section{REFERENCES}

[1] Atapaththu, K. S. S., Asaeda, T., Yamamuro, M., Kamiya, H. (2017): Effects of water turbulence on plant, sediment and water quality in reed (Phragmites australis) community. - Ekologia Bratislava 6: 1-9.

[2] Banerjee, A., Roychoudhury, A. (2016): Group II late embryogenesis abundant (LEA) proteins: structural and functional aspects in plant abiotic stress. - Plant Growth Regulation 79: 1-17.

[3] Borrell, A. K., Incoll, L. D., Simpson, R. J., Dalling, M. J. (1989): Partitioning of Dry Matter and the Deposition and Use of Stem Reserves in a Semi-dwarf Wheat Crop. Annals of Botany 63: 527-539.

[4] Chaves, M. M., Flexas, J., Pinheiro, C. (2008): Photosynthesis under drought and salt stress: regulation mechanisms from whole plant to cell. - Annals of Botany 103: 551-560.

[5] Cullen, B. R., Chapman, D. F., Quigley, P. E. (2005): Carbon resource sharing and rhizome expansion of Phalaris aquatica plants in grazed pastures. - Functional Plant Biology 32: 79-85.

[6] Dong, M., Yu, F. H., Chen, Y. F., Song, M. H., Liu, J., Chen, J. S., Li, J. M., Liu, F. H. (2011): Clonal plant ecology. - Beijing: science press.

[7] Douhovnikoff, V., Dodd, R. S. (2015): Epigenetics: a potential mechanism for clonal plant success. - Plant Ecology 216: 227-233.

[8] Eklöf, J. S., McMahon, K., Lavery, P. S. (2009): Effects of multiple disturbances in seagrass meadows: shading decreases resilience to grazing. - Marine and Freshwater Research 60: 1317-1327.

[9] Fernandez, E., Baird, G., Farías, D., Oyanedel, E., Olaeta, J. A., Brown, P., Zwieniecki, M., Tixier, M. A., Saa, S. (2018): Fruit load in almond spurs define starch and total soluble carbohydrate concentration and therefore their survival and bloom probabilities in the next season. - Scientia Horticulturae 237: 269-276.

[10] Finlayson, C. M., Everard, M., Irvine, K., McInnes, R. J., Middleton, B. A., Van Dam, A. A., Davidson, N. C. (2018): Preface: The wetland book. Vol. 1: Wetland structure and function, management, and method. - Springer, 2290p.

[11] Ganie, A. H., Reshi, Z. A., Wafai, B. A., Puijalon, S. (2015): Clonal growth architecture and spatial dynamics of 10 species of the genus potamogeton across different habitats in Kashmir Valley, India. - Hydrobiologia 767: 289-299.

[12] Ge, T. D., Sun, N. B., Bai, L. P., Tong, C. L., Sui, F. G. (2012): Effects of drought stress on phosphorus and potassium uptake dynamics in summer maize (Zea mays) throughout the growth cycle. - Acta Physiol Plant 34: 2179-2186.

[13] Gričar, J., Zavadlav, S., Jyske, T., Lavrič, M., Laakso, T., Hafner, P., Eler, K., Vodnik, D. (2018): Effect of soil water availability on intra-annual xylem and phloem formation and non-structural carbohydrate pools in stem of Quercus pubescens. - Tree Physiology 39: 222-233.

[14] Guo, Q. X., Li, J. Y., Zhang, Y. X., Zhang, J. X., Lu, D. L., Korpelainen, H., Li, C. Y. (2016): Species-specific competition and $\mathrm{N}$ fertilization regulation-structural carbohydrate contents in two Larix species. - Forest Ecology and Management 364: 60-69.

[15] Harper, J. L. (1977): Population Biology of Plant. - London and New York: Academic Press.

[16] Hinman, E. D., Fridley, J. D. (2018): To spend or to save? Assessing energetic growthstorage tradeoffs in native and invasive woody plants. - Oecologia 188: 659-669.

[17] Hoch, G., Richter, A., Körner, C. (2003): Non-structural carbon compounds in temperate forest trees. - Plant Cell \& Environment 26: 1067-1081.

[18] Hutchings, M. J., Wijesinghe, D. K. (2008): Performance of a clonal species in patchy environments: effects of environmental context on yield at local and whole-plant scales. Evolutionary Ecology 22: 313-324. 
[19] Ivanov, Y. V., Kartashov, A. V., Zlobin, I. E., Sarvin, B., Stavrianidi, A. N., Kuznetsov, V. V. (2019): Water deficit-dependent changes in non-structural carbohydrate profiles, growth and mortality of pine and spruce seedlings in hydroculture. - Environmental and Experimental Botany 157: 151-160.

[20] Jiao, L., Zhou, Y., Liu, X., Wang, S., Li, F. (2020): Driving forces analysis of non-structural carbohydrates for Phragmites australis in different habitats of inland river wetland. - Water 12: 1700 .

[21] Kaur, J., Thakur, S. S. (2016): Characterization of carbohydrates and proteins in phalaris minor seeds by cornell net carbohydrate and protein system. - Current Science A Fortnightly Journal of Research 110: 1324-1329.

[22] Klein, T., Hoch, G., Yakir, D., Korner, C. (2014): Drought stress, growth and nonstructural carbohydrate dynamics of pine trees in a semi-arid forest. - Tree Physiology 34: 981-992.

[23] Kleyer, M., Trinogga, J., Cebrián-Piqueras, M. A., Trenkamp, A., Fløjgaard, C., Ejrnaes, R., Blasius, B. (2018): Trait correlation network analysis identifies biomass allocation traits and stem specific length as hub traits in herbaceous perennial plants. - Journal of Ecology 107: 829-842.

[24] Landhäusser, S. M., Chow, P. S., Dickman, L. T., Furze, M. E., Kuhlman, I., Schmid, S. (2018): Standardized protocols and procedures can precisely and accurately quantify nonstructural carbohydrates. - Tree Physiology 38: 1764-1778.

[25] Lapointe, L. (2001): How phenology influences physiology in deciduous forest spring ephemerals. - Physiologia Plantarum 113: 151-157.

[26] Li, M. H., Xiao, W. F., Wang, S. G., Cheng, G. W., Cherubini, P., Cai, X. H. (2008): Mobile carbohydrates in Himalayan treeline trees I. Evidence for carbon gain limitation but not for growth limitation. - Tree Physiology 28(8): 1287-1296.

[27] Li, L., Lan, Z., Chen, J., Song, Z. (2018): Allocation to clonal and sexual reproduction and its plasticity in Vallisneria spinulosa along a water-depth gradient. - Ecosphere 9: e02070.

[28] Li, T. T., Xue, J. Q., Wang, S. L., Xue, Y. Q., Hu, F. R., Zhang, X. X. (2018): Research advances in the metabolism and transport of non-structural carbohydrates in plants. - Plant Physiology Journal 54: 25-35.

[29] Liu, L. D., Jie, D. M., Liu, H. Y., Gao, G. Z., Gao, Z., Li, D. H., Li, N. N., Guo, J. X., Qiao, Z. H. (2016): Assessing the importance of environmental factors to phytoliths of Phragmites communis in north-eastern China. - Ecological Indicators 69: 500-507.

[30] Lloret, F., Sapes, G., Rosas, T., Galiano, L., Saura-Mas, S., Sala, A., Martínez-Vilalta, J. (2018): Non-structural carbohydrate dynamics associated with drought-induced die-off in woody species of a shrubland community. - Annals of Botany 121: 1383-1396.

[31] Loewe, A., Einig, W., Shi, L. B., Dizengremel, P., Hampp, R. (2000): Mycorrhiza formation and elevated $\mathrm{CO}_{2}$ both increase the capacity for sucrose synthesis in source leaves of spruce and aspen. - New Phytologist 145: 565-574.

[32] Lv, Y. Y., Li, D. Z., Xu, J., Xu, L. L., Gao, J. J., Pan, Y., Zhao, M. X., Cheng, L. L., Wang, H., He, Y. Y. (2013): Spatial and Temporal Characteristics of Non-structural Carbohydrates Contents of Phragmites australis and Spartina alterniflora at Chongming Dongtan Wetland. - Journal of Northeast Forestry University 41: 85-89+121.

[33] Martinez-Vilalta, J., Sala, A., Asensio, D. (2016): Dynamics of non-structural carbohydrates in terrestrial plants: a global synthesis. - Ecological Monographs 86: 495516.

[34] Martyniuk, C. J., Doperalski, N. J., Prucha, M. S., Zhang, J. L., Kroll, K. J., Conrow, R., Barber, D. S., Denslow, N. D. (2016): High contaminant loads in Lake Apopka's riparian wetland disrupt gene networks involved in reproduction and immune function in largemouth bass. - Comparative Biochemistry \& Physiology Part D Genomics \& Proteomics 19: 140-150.

[35] Mataa, M., Tominaga, S., Kozaki, I. (1996): Seasonal Changes of Carbohydrate Constituents in Ponkan (Citrus reticulata Blanco). - Engei Gakkai Zasshi 65: 513-523. 
[36] Michelot, A., Simard, S., Rathgeber, C., Dufrene, E., Damesin, C. (2012): Comparing the intra-annual wood formation of three European species (Fagus sylvatica, Quercus petraea and Pinus sylvestris) as related to leaf phenology and non-structural carbohydrate dynamics. - Tree Physiology 32(8): 1033-1045.

[37] Mudrák, O., Fajmon, K., Jongepierová, I., Prach, K. (2017): Mass effects, clonality, and phenology but not seed traits predict species success in colonizing restored grasslands. Restoration Ecology 26: 489-496.

[38] Myers, J. A., Kitajima, K. (2007): Carbohydrate storage enhances seedling shade and stress tolerance in a neotropical forest. - Journal of Ecology 95: 383-395.

[39] Nathan, G. M., Sevanto, S. (2010): The mechanisms of carbon starvation: how, when, or does it even occur at all? - New Phytologist 186: 264-266.

[40] Ooi, J. L. S., Kendrick, G. A., Van Niel, K. P. (2011): Effects of sediment burial on tropical ruderal seagrasses are moderated by clonal integration. - Continental Shelf Research 31: 1945-1954.

[41] Orthen, B., Wehrmeyer, A. (2004): Seasonal dynamics of non-structural carbohydrates in bulbs and shoots of the geophyte Galanthus nivalis. - Physiol Plantarum 120: 529-536.

[42] Packer, J. G., Meyerson, L., Skálová, H., Pyšek, P., Kueffer, C. (2017): Biological Flora of the British Isles: Phragmites australis. - Journal of Ecology 105: 1123-1162.

[43] Petrussa, E., Boscutti, F., Vianello, A., Casolo, V. (2018): 'Last In-First Out': Seasonal variations of non-structural carbohydrates, glucose-6-phospate and ATP in tubers of two Arum species. - Plant Biology 20: 346-356.

[44] Piper, F. I., Fajardo, A., Hoch, G. (2017): Single-provenance mature conifers show higher non-structural carbohydrate storage and reduced growth in a drier location. - Tree Physiology 37: 1001-1010.

[45] Portela, R., Barreiro, R., Roiloa, S. R. (2018): Biomass partitioning in response to resources availability: A comparison between native and invaded ranges in the clonal invader Carpobrotus edulis. - Plant Species Biology 34: 11-18.

[46] Pramanik, M. H. R., Shelley, I. J., Adhikary, D., Islam, M. O. (2016): Carbohydrate reserve and aerenchyma formation enhance submergence tolerance in rice. - Progressive Agriculture 27: 256-264.

[47] Purdy, S. J., Maddison, A. L., Cunniff, J., Donnison, I., Clifton-brown, J. (2015): Nonstructural carbohydrate profiles and ratios between soluble sugars and starch serve as indicators of productivity for a bioenergy grass. - Aob Plants 7: 032-042.

[48] Qin, X., Feng, L., Chen, X., Xie, Y. (2013): Growth responses and non-structural carbohydrates in three wetland macrophyte species following submergence and desubmergence. - Acta Physiol. Plant. 35: 2069-2074.

[49] Quentin, A. G., Pinkard, E. A., Ryan, M. G., Tissue, D. T., Baggett, L. S., Adams, H. D., Gibon, Y. (2015): Non-structural carbohydrates in woody plants compared among laboratories. - Tree Physiology 35: 1146-1165.

[50] Regier, N., Streb, S., Zeeman, S. C., Frey, B. (2010): Seasonal changes in starch and sugar content of poplar (Populus deltoides x nigra cv. Dorskamp) and the impact of stem girdling on carbohydrate allocation to roots. - Tree Physiology 30: 979-987.

[51] Reis, V., Hermoso, V., Hamilton, S. K., Ward, D., Fluet-Chouinard, E., Lehner, B., Linke, S. (2017): A global assessment of inland wetland conservation status. - Bioscience 67: 523533.

[52] Sala, A., Woodruff, D. R., Meinzer, F. C. (2012): Carbon dynamics in trees: feast or famine? - Tree Physiology 32: 764-775.

[53] Savage, J. A., Clearwater, M. J., Haines, D. F., Klein, T., Mencuccini, M., Sevanto, S., Turgeon, R., Zhang, C. (2015): Allocation, stress tolerance and carbon transport in plants: how does phloem physiology affect plant ecology? - Plant Cell Environ 39: 709-725.

[54] Schaberg, P. G., Snyder, M. C., Shane, J. B., Donnelly, J. R. (2000): Seasonal patterns of carbohydrate reserves in red spruce seedlings. - Tree Physiology 20: 549-555. 
[55] Sevanto, S., McDowell, N. G., Dickman, L. T., Pangie, R., Pockman, W. T. (2013): How do trees die? A test of the hydraulic failure and carbon starvation. - Plant Cell \& Environment 37: 153-161.

[56] Shi, P. L., Körner, C., Hoch, G. (2006): End of season carbon supply status of woody species near the tree line in western China. - Basic \& Applied Ecology 7: 370-377.

[57] Shi, C. G., Silva, L. C. R., Zhang, H. X., Zheng, Q. Y., Xiao, B. X., Wu, N., Sun, G. (2015): Climate warming alters nitrogen dynamics and total non-structural carbohydrate accumulations of perennial herbs of distinctive functional groups during the plant senescence in autumn in an alpine meadow of the Tibetan Plateau, China. - Agricultural and Forest Meteorology 200: 21-29.

[58] Sørensen, S. T., Campbell, M. L., Duke, E., Manley-Harris, M. (2018): A standard, analytical protocol for the quantitation of non-structural carbohydrates in seagrasses that permits inter-laboratory comparison. - Aquatic Botany 151: 71-79.

[59] Sun, X. M., He, M. Z., Zhou, B., Li, J. X., Chen, N. L. (2020): Non-structural carbohydrates and $\mathrm{C}: \mathrm{N}: \mathrm{P}$ stoichiometry of roots, stems, and leaves of Zygophyllum xanthoxylon in responses to xeric condition. - Arid Land Geography 44: 240-249.

[60] Svensson, B. M., Rydin, H., Carlsson, B. A. (2013): Clonality in the plant community. Veg Ecol Second Edition.

[61] Trifilò, P., Casolo, V., Raimondo, F., Petrussa, E., Boscutti, F., Gullo, M. A. L., Nardini, A. (2017): Effects of prolonged drought on stem non-structural carbohydrates content and post-drought hydraulic recovery in Laurus nobilis L.: The possible link between carbon starvation and hydraulic failure. - Plant Physiol Biochem 120: 232-241.

[62] Tursun, N., Seyithanoglu, M., Uygur, F. N. (2011): Seasonal dynamics of soluble carbohydrates in rhizomes of Phragmites australis and Typha latifolia. - Flora 206: 731735.

[63] Veneklaas, E., J den Ouden, F. (2005): Dynamics of non-structural carbohydrates in two Ficus species after transfer to deep shade. - Environmental \& Experimental Botany 54: 148-154.

[64] Wan, J. Z., Wang, C. J., Yu, F. H. (2019): Large-scale environmental niche variation between clonal and non-clonal plant species: Roles of clonal growth modules and ecoregions. - The Science of the Total Environment 652: 1071-1076.

[65] Wang, B., Jiang, Y., Wang, M. C., Dong, M. Y., Zhang, Y. P. (2015): Variations of nonstructural carbohydrate concentration of Picea meyeri at different elevations of Luya Mountain, China. - Chinese Journal of Plant Ecology 39: 746-752.

[66] Wang, S., Ding, Y., Lin, S., Ji, X., Zhan, H. (2015): Seasonal changes of endogenous soluble sugar and starch in different developmental stages of Fargesia yunnanensis. Journal of Wood Science 62: 1-11.

[67] Würth, M. K. R., Peláez-Riedl, S., Wright, S. J., Körner, C. (2004): Non-structural carbohydrate pools in a tropical forest. - Oecologia 143: 11-24.

[68] Xiao, Y. A., Dong, M., Wang, N., Lan, L. L. (2015): Effects of modules removal on tradeoffs between sexual and clonal reproduction in the stoloniferous herb Duchesnea indica.Plant Species Biology 31: 50-54.

[69] Xiao, L., Liu, G. B., Li, P., Xue, S. (2017): Responses of photosynthesis and non-structural carbohydrates of Bothriochloa ischaemum to doubled $\mathrm{CO}_{2}$ concentration and drought stress. - Journal of Plant Nutrition and Fertilizer 23: 389-397.

[70] Yin, J. J., Guo, D. L., He, S. Y., Zhang, L. (2009): Non-structural carbohydrate, N, and P allocation patterns of two temperate tree species in a semi-arid region of Inner Mongolia. - Acta Scientiarum Naturalium Universitatis Pekinensis 45: 519-527.

[71] Yu, D. P., Wang, Q. W., Liu, J. Q., Zhou, W. M., Qi, L., Wang, X. Y., Zhou, L., Dai, L. M. (2014): Formation mechanisms of the alpine Erman's birch (Betula ermanii) treeline on Changbai Mountain in Northeast China. - Trees 28: 935-947. 
[72] Zhou, Y., Jiao, L., Qin, H. J., Li, F. (2022): Effect of Environmental Stress on the Nutrient Stoichiometry of the Clonal Plant Phragmites australis in Inland Riparian Wetlands of Northwest China. - Frontiers in Plant Science 12: 705319.

[73] Zhu, B. J., Yin, B. F., Zhang, Y. M. (2017): Seasonal dynamics of non-structural carbohydrate contents of Syntrichia caninervis among different microhabitats. - Journal Desert Research 37: 268-275. 